\title{
溝加エが施されたサファイアウエハのレーザ割断*
}

\author{
上田 隆司 ${ }^{* 1}$ ，松永 隆秀 ${ }^{* 2}$ ，古本 達明*1

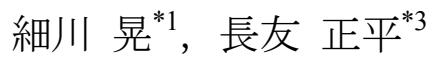

\section{Laser Cleaving of Sapphire Wafer with Pre-Groove}

\author{
Takashi UEDA*1, Takahide MATSUNAGA, Tatsuaki FURUMOTO, \\ Akira HOSOKAWA and Shouhei NAGATOMO \\ ${ }^{* 1}$ Kanazawa Univ. Dept. of Mechanical Engineering \\ Kakuma-machi, Kanazawa, 920-1192, Japan
}

Sapphire wafer with pre-groove is cleaved by the irradiation of continuous $\mathrm{CO} 2$ laser. The width of groove is $5 \mu \mathrm{m}$ and the depth is $15 \mu \mathrm{m}$. The groove is made by the irradiation of third harmonic wave of Nd:YAG laser whose wavelength is $322 \mu \mathrm{m}$. The pre-groove plays the initial crack which is conventionally introduced by pressing the diamond indenter in laser cleaving. The crack is induced from the pre-groove by the irradiation of laser beam and propagates along the pre-groove and as a result the wafer is divided. The surface roughness of the cleaved surface is very smooth and the surface roughness is smaller than $0.1 \mu \mathrm{m}$. Using the pre-groove makes possible to propagate the crack cross the cleaved surface of the wafer.

Key Words : Laser Processing(1064), Sapphire, Laser Cleaving, Pre-Groove, CO2 Laser

\section{1. 緒言}

サファイアは，高硬度かつ高熱伝導の材料であり，可視光に対する優れた光透過性を有しており，近年ではLED チップの基板などの用途に広く用いられている．硬脆材料であるサファイアを分断するにはダイヤモンドブレー ドによる切断やスクライビングなどが行われているが，容易ではない(1) (2).レーザ割断はレーザ照射により生じ た熱忘力を利用し亀裂を進展させる加工法であり, 加工液・消耗工具・切り代が不要であり, 非接触で加工でき ることから外力が働かないといった特長を持っている，ところが，レーザ割断は原理上，亀裂進展の起点となる 初期亀裂が必要であり, ビッカース圧子などにより初期亀裂を導入しなければならない(3)(4). また, 亀裂を横断 して亀裂進展させることができないことから，十字状に亀裂を進展させて分断することができない. さらに，熱 応力を利用して亀裂を進展させていることから， ウエハが小さくなるとエッジ部の影響を受けることになり，割 断幅を狭くして細かく分断することが難しいなどの問題点がある.

そこで，本研究ではレーザ割断のもつこれらの欠点を克服する新しい試みとして， ウエハ上に前もって十数ミ クロンの深さの浅い溝を加工しておき，この溝に沿って亀裂を伝搬させ， ウエハをチップ状に分断する方法を提 案している. この溝が亀裂進展の起点となることから，これまでのような初期溝を導入することが不要である. 亀裂が溝に沿って進展することから割断幅の小さい加工が可能となり, また，溝を十字状にクロスさせて作って おくことにより, 断面を横断して亀裂伝搬が可能となり, 小さなチップの製作が可能となるなど（本研究では,

* 原稿受付 2013 年 4 月 21 日

*1 正員, 金沢大学 (下920-1192 石川県金沢市角間町)

$*_{2}$ 金沢大学理工学域

*3 三星ダイヤモンド工業(株)（广566-0034 大阪府捸津市香露園 32-12）

E-mail: ueda@se.kanazawa-u.ac.jp 
0.25 mm幅のチップ製作を目標），これまでのレーザ割断の弱点を克服することができる.

\section{2. 実験方法}

\section{$2 \cdot 1$ サファイアウエハと溝加エ}

実験に使用したサファイアウエハを図1に示す，表面は(0001)面であり， [-1-12 0]方向に亀裂を進展させてい る. 表面は研磨仕上げされており, ウエハの厚さは $150 \mu \mathrm{m}$ である. ウエ八上の初期溝の加工は, 波長 $355 \mathrm{~nm}$ の $\mathrm{Nd}$ : YAGレーザ(3倍波)を用いて行っている.（a) は十字状に溝を入れたウエ八を上から見ており，(b) はウエ八断面を 見ており，溝の幅が $5 \mu \mathrm{m}$ ，深さが $15 \mu \mathrm{m}$ である．幅 $a$ のファイアを準備し， $a$ を 2 等分する位置に 1 本の溝を入 れて試料としている. 本研究では試料幅を $a=24 \mathrm{~mm} \sim 0.50 \mathrm{~mm}$ 間で変化させており, 目標の $0.25 \mathrm{~mm}$ のップを 製作するには $=0.50 \mathrm{~mm}$ の試料を割断することになる.

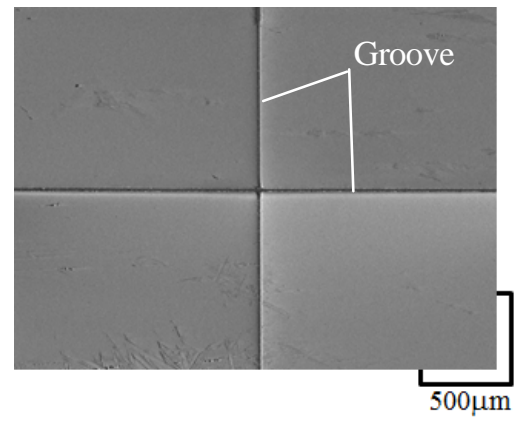

(a) Top view of sapphire specimen

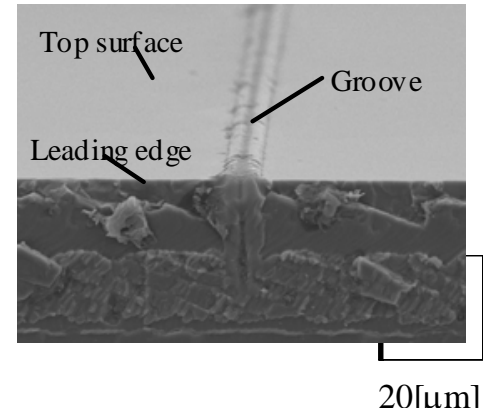

(b) Side view of sapphire specimen

Fig.1 Pre-groove made in surface of Sapphire wafer

\section{$2 \cdot 2$ 実験装置と実験条件}

実験には，レーザ微細加工システムRAPYULAS MPT-1030 (三星ダイヤモンド工業（株）製)を用いた。レンズの焦 点を試料表面より上部に合わせることによりデフォーカスを与え，ビーム径を $d=58.3 \sim 717 \mu \mathrm{m} の$ 間で変化さ せる． 実験条件を表 1 に示す．レーザ光はウエ八の外からスタートさせ, 前もって導入されている溝の中心線に レーザ光の中心を合わせて一定速度 $V=5 \mathrm{~mm} / \mathrm{s}$ でレーザ光をスキャンすることにより割断を行った. レーザパワ 一は $Q=3.0 \sim 9.0 \mathrm{~W}$ の間で変化させた.

Table 1 Experimental conditions

\begin{tabular}{llll}
\hline Laser & \multicolumn{3}{c}{$\mathrm{CO}_{2}$ laser } \\
Wave length & {$[\mu \mathrm{m}]$} & $\lambda$ & 10.6 \\
Irradiation mode & & \multicolumn{3}{c}{ Continuous wave } \\
Laser power & {$[\mathrm{W}]$} & $Q$ & $3.0 \sim 9.0$ \\
Defocus & {$[\mathrm{mm}]$} & $d f$ & $0 \sim 2.4$ \\
Beam diameter & {$[\mu \mathrm{m}]$} & $d$ & $58.3 \sim 717$ \\
Energy density & {$\left[\mathrm{J} / \mathrm{mm}^{2}\right]$} & $P$ & $2.23 \sim 20.58$ \\
\hline Specimen & & Sapphire wafer (c-plane) \\
Groove depth & {$[\mu \mathrm{m}]$} & \multicolumn{3}{c}{15} \\
Width of specimen & {$[\mathrm{mm}]$} & $a$ & $24 \sim 0.50$ \\
Thickness & {$[\mu \mathrm{m}]$} & $t$ & 150 \\
Feed rate & {$[\mathrm{mm} / \mathrm{s}]$} & $V$ & 5.0 \\
\hline
\end{tabular}




\section{3. 実験結果及び考察}

割断結果の評価であるが，亀裂が伝搬してウエハを分断できたか，亀裂が溝に沿って伝搬したか，熱応力でウ エハが破壊していないか，割断面の粗さは小さいか，などで判断することにする．目指しているレーザ割断は， 溝に沿って亀裂を伝播させてウエ八を分断し，かつ割断面の表面粗さが0.1 $\mu$ m以下となるレベルである.

\section{$3 \cdot 1$ レーザパワーの影響}

幅 $a=1.0 \mathrm{~mm}$ のサファイアに対し，レーザパワーQを変化させて割断実験を行った．図 2 は溝に沿って亀裂が伝 搬してウエハの分断に成功した結果を示している. 割断面の最大高さ $P Z$ を測定することにより, 割断の精度を示 している．レーザパワーQが $7 \mathrm{~W}$ まで，すなわち照射したレーザのエネルギー密度 $p$ が $4.2 \mathrm{~J} / \mathrm{mm}^{2}$ までは $P Z$ は非常 に小さく, 高精度の割断が行われていることがわかる. ところが, レーザパワー $Q=8.0$ Wになり, エネルギー密 度 $p$ が $4.8 \mathrm{~J} / \mathrm{mm}^{2}$ になると, $P Z$ は急激に大きくなり, 割断の精度が大きく低下していることがわかる.

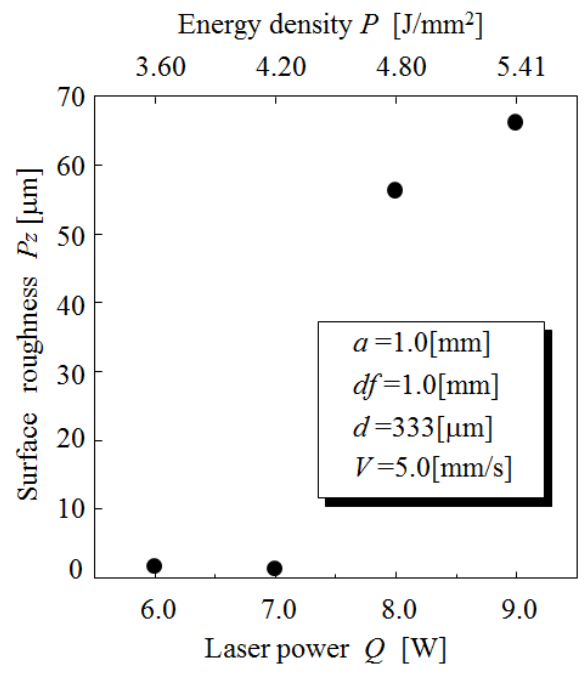

Fig.2 Variation of surface roughness $P z$ with laser power $Q$

このときの割断面の写真を図 3 に示寸. 図(a) はウエ八の断面であるが, 上面に前もって加工した溝の跡が残っ ている. 深さ約 $15 \mu \mathrm{m}$ である. 溝から下が割断した面であるが, 鏡面となっており, 面粗さは非常に小さい. こ れ対し，図(b)では，上面近傍に溝の跡が残っているが，溝から下の部分には大きなうねりを生じており，我々が

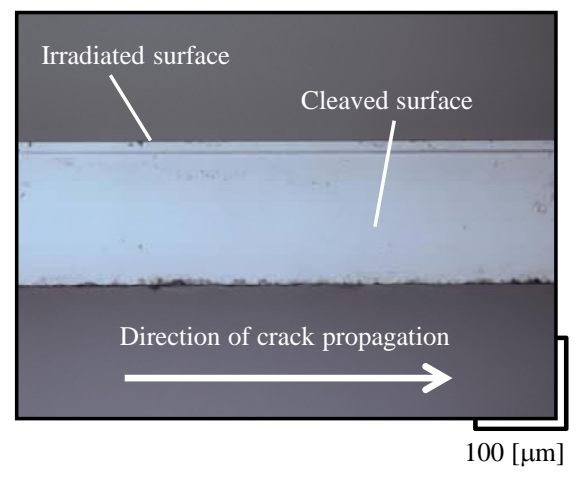

(a) Laser power: $\mathrm{Q}=7[\mathrm{~W}]$

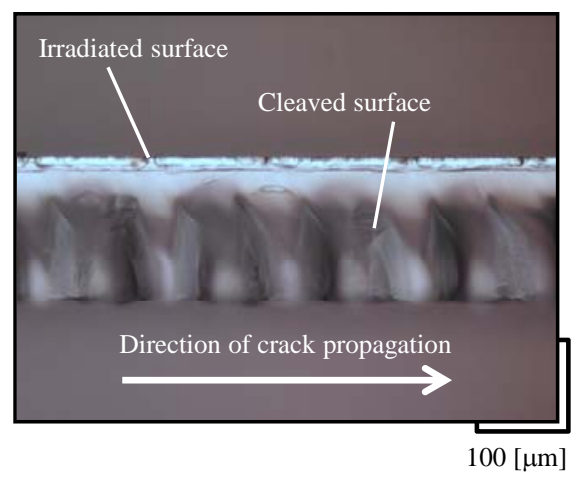

(b) Laser power : Q=9 [W]

Fig.3 Image of cleaved surface $(a=1.0[\mathrm{~mm}], \quad d f=1.0[\mathrm{~mm}], \quad d=333[\mu \mathrm{m}], \quad V=5.0[\mathrm{~mm} / \mathrm{s}])$ 
望む割断面が得られていない，このように，照射するレーザのエネルギ一密度がある限界を越えると急激に割断 面の粗さが悪くなり，時には試料が粉々に破壊される場合も出てくる. 試料幅の小さな試料ではエネルギーの影 響が大きく現れることになり，割断条件の設定が難しくなることがわかる.

\section{$3 \cdot 2$ 試料幅の影響}

図 4 は, レーザパワーQ $=9 \mathrm{~W}\left(p=5.41 \mathrm{~J} / \mathrm{mm}^{2}\right)$ と一定にして, 試料幅 $a$ を変えて割断を行ったときの, 割断面 での最大高さ $P Z$ の変化を示寸. 試料幅 $a$ が $4.0 \mathrm{~mm}$ まではPZの大きさに大きな変化はなく, ほぼ一定である. し かし, 試料幅 $a$ が $1.0 \mathrm{~mm}$ になると, 急激に $P$ Zが大きくなっている. エネルギー密度 $p$ が $p=5.41 \mathrm{~J} / \mathrm{mm}^{2}$ と大き いことから，試料幅が大きい場合は安定した割断が行われているが， $a=2 \mathrm{~mm}$ 以下になるとレーザ照射部の温度 が上昇しやすくなり, 発生する熱応力が大きくなって亀裂の伝搬が不安定となり, 割断面が粗くなってしまうと 考えられる ${ }^{5}$. さらに試料幅の小さい $a=1 \mathrm{~mm}$ になると温度が高くなるため, 図 3 (b)に示したように, 割断面の PZは非常に大きくなってしまう，試料サイズが小さくなると温度が上昇しやすくなるため，加工条件の設定が難 しくなることがわかる.

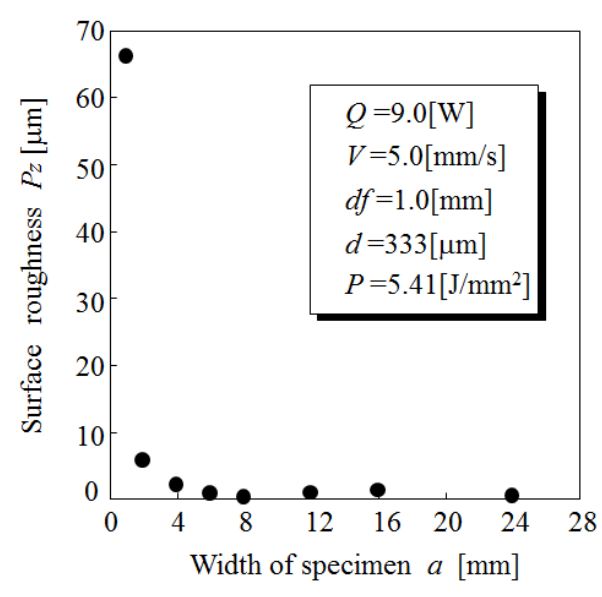

Fig.4 Influence of width of specimen on roughness of cleaved surface

以上の結果を基に適切なレーザ照射条件を見つけ出し, 試料幅 $a=12 \mathrm{~mm} \sim 0.50 \mathrm{~mm}$ のサファイアウエハを割 断した結果から， $a=2.0 \sim 0.5 \mathrm{~mm}$ の写真を図 5 に示寸. サイズが小さくなるにつれて割断が可能となるレー

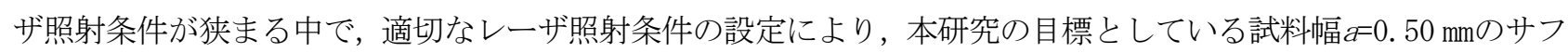
アイアウエハ試料のレーザ割断が可能となっている.

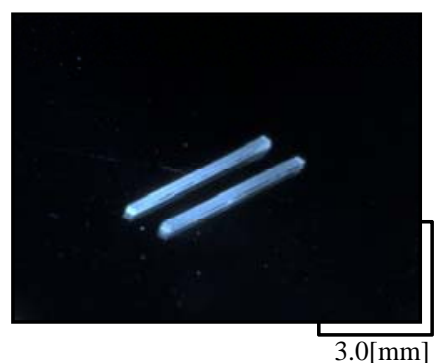

(a) Width of specimen : $a=0.5[\mathrm{~mm}]$

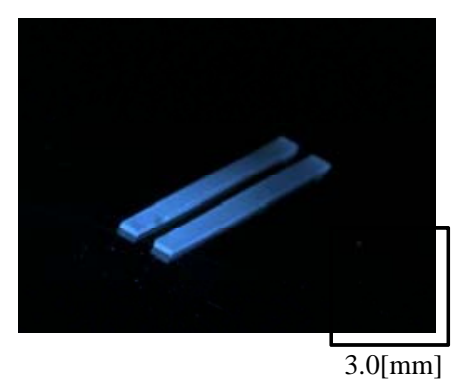

(b) Width of specimen : $a=1.0[\mathrm{~mm}]$

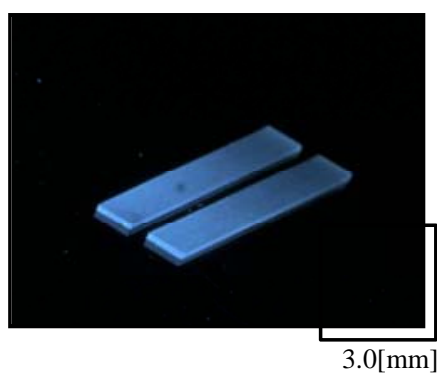

(c) Width of specimen : $a=2.0[\mathrm{~mm}]$

Fig. 5 Sapphire wafer after laser cleaving 


\section{$3 \cdot 3$ 十字状の溝が施されたサファイアウエハの割断}

一枚のサファイアウエハ試料から 4 枚のウエハを切り出すことを目的とし, 試料表面に十字状に溝を加工した サファイアウエハを使用して割断加工を行った. 試料表面の結晶方位は $\left(\begin{array}{llll}0 & 0 & 0 & 1\end{array}\right)$ 面で, 試料厚さは $t=150 \mu \mathrm{m}$ で

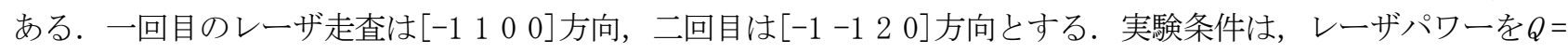

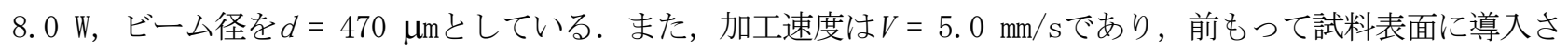
れた加工溝の深さは10 $\mu \mathrm{m}$ とした.

図 6 は4 分割したサファイアウエハを上部から見た写真である. まず, (1)方向に亀裂を進展させ, ウエハを 2 分している．その状態を保ったまま(2)方向に亀裂を進展させることで4枚のチップに分断している．前もって溝 が加工されていることで，すでに分断されている(1)方向の断面を乗り越えて(2)方向に亀裂を進展させることが可 能となっている. また, 溝から逸れることなく亀裂が進展しており, 割断面あらさも $0.1 \mu \mathrm{m}$ 以下と極めて良好 な割断が行われている.

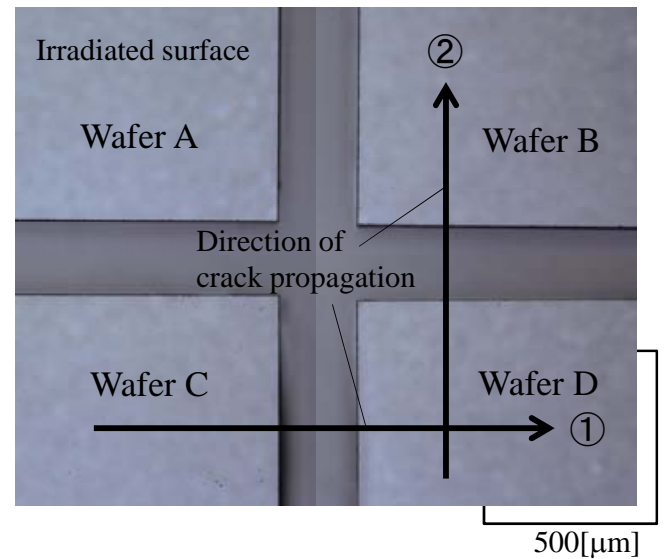

Fig.6 Sapphire wafer divided to four pieces by laser cleaving

\section{4. 結 言}

サファイアウエハに前もって溝を施し，この溝に沿って亀裂を進展させることによりウエハを分断する方法を 提案している.この方法により, 初期亀裂の導入が不要となり, 小さな試料の分断が可能となり, 十字状に亀裂 を進展させることでウエ八をチップ状に分断することが可能となり，これまでのレーザ割断において大きな問題 となっていた $3 つ の$ 短所を克服できる可能性を示すことができた.

\section{文献}

（1）菅田 充, “サファイア基板光半導体のレーザ割断法”, 砥粒加工学会誌, Vol. 49, No. 4 (2005), pp. 191-194.

（2）長友正平, 小川純一, 西條敦弘, 栗山規由, “レーザによる硬脆性材料のスクライビング加工”, 第 65 回レーザ加 工学会講演論文集, (2005), pp. 207-210.

(3) 上田隆司, 三野大樹, 古本達明, 細川 晃, 長友正平, “CO2 パルスレーザによるサファイアウエハの熱応力割断”, 砥粒加工学会誌, Vol. 55, No. 7 (2011), pp. 424-426.

(4) 上田隆司, 田中邦茂, 西岡慎吾, 山田啓司, 細川 晃, “電子デバイス用ウエハのレーザ割断”, 精密工学会誌, Vol. 75, No. 3, (2009), pp. 443-445.

(5) 山田啓司, 大磯桂一, 細川 晃, 上田隆司, “パルス YAG レーザによる Si ウエハの割断機構に関する研究”, 精密 工学会, Vo. 67, No.11, (2001), pp.1861-1865. 